\title{
UV Protection and Wettability Properties for Cotton Fabric Using ZnO Nanoparticles
}

\author{
*Nilgün BECENEN
}

\begin{abstract}
Ultra-violet protection and Wettability Properties of nano zinc oxide $(\mathrm{ZnO})$ with acrylic binder has been assessed on the cotton fabric using pad-dry-cure method. The nano $\mathrm{ZnO}$ finished cotton fabrics are tested for ultraviolet protection factor and wettability properties. The UV properties of the treated fabric were investigated by using UV/Vis transmittance analyzer. Wettability Properties was evaluated using contact angles (CA) by a KSV/Attension Theta Tensiometer. UV tests indicated a significant improvement in the UVabsorbing activity of the $\mathrm{ZnO}$ coated cotton fabric. The coatings made by the nano materials were increased hydrophobic properties by means of changing wetting capability of cotton fabric surface.
\end{abstract}

Keywords-Nano coating, cotton Fabric, Wettability, Contact Angle, Ultra-violet protection.

\section{INTRODUCTION}

Nanocoating the surface of textiles, clothing, and textiles for footwear is one approach used to produce highly active surfaces with UV-blocking, antimicrobial and self-cleaning properties. Nanoparticle coating may affect other fabric properties like dyeing properties, strength, bending rigidity and air permeability. Fabric friction, which is defined as the resistance to motion, can play a crucial role in the textile industrie [1].

The wettability is the force that drives the penetration by liquid and it depends on the surface energy and roughness of the material. In many applications low wettability of a finished fabric is important for uses including as rainwear, protective clothing $[2,3]$ and automotive interior fabrics.

Low wettability is one of the most important requirements for these materials, which strongly depends on two properties: the surface free energy and the surface roughness. Textiles are composed of fibres that provide inherent micro-scaled surface roughness [4]. Finally, it is easy to make textiles hydrophobic by coating them with an appropriate hydrophobic reagent [5].

For the first time in this study, $\mathrm{ZnO}$ nanomaterials were prepared and applied onto cotton fabric by using an acrylic binder. The hydrophobic wettability and Ultra-violet protection properties of this fabric were evaluated.

*Trakya University, Vocational College of Technical Sciences, 22030 Edirne/TURKEY

\section{II.EXPERIMENTAL}

\section{A. Material and Measurements}

Nanomaterials were applied to the face side of the $100 \%$ cotton fabric. (Weight of Cotton fabric was $30 / 1,152 \mathrm{~g} / \mathrm{m}^{2}$ ) with concentration of $1 \%$, material to liquor ratio $1: 20$, and acrylic binder $1 \%$. The fabric was cut to the size of $30 \times 30$ $\mathrm{cm}$ and was coated with nanomaterials by using a spray gun.

The UV properties of the treated fabric were investigated by using UV/Vis transmittance analyzer. The blank reference was air. The UV properties of the untreated samples were compared with the spectra collected from the same fabric treated with $\mathrm{ZnO}$ nano materials and the effectiveness in shielding UV radiation was evaluated by measuring the UV absorption, transmission and reflection.

The contact angle values of $\mathrm{ZnO}$ nanomaterial-untreated and treated dyed cotton fabrics were measured with KSV/Attension Theta Tensiometer.

\section{ResUlts}

\section{A. UV properties}

Solar UV radiation is composed of UV-A (400-315 nm), UV-B (315-290 nm) and UV-V (290-200 nm) (Table 1). UV spectra were recorded for untreated and treated cotton fabrics by measuring the absorbance, transmission and reflection. Untreated fabric did not absorb UV radiation while the treatment with nanosized $\mathrm{ZnO}$, particles on the cotton fabrics increased the absorption of UV light over the entire investigated UV spectrum.

TABLE I

\begin{tabular}{lclcc}
\multicolumn{4}{c}{ UPF VALUES OF ZNO NANOMATERIAL-TREATED COTTON FABRIC } \\
\hline $\begin{array}{l}\text { Fabric } \\
\text { sample }\end{array}$ & $\begin{array}{l}\text { UPF } \\
\text { values }\end{array}$ & Protection & UV-A values & $\begin{array}{c}\text { UV-B } \\
\text { values }\end{array}$ \\
\hline Untreated & 7.11 & $\begin{array}{l}\text { Insufficient } \\
\text { protection }\end{array}$ & 18.30 & 13.36 \\
Nano ZnO & 35.52 & $\begin{array}{l}\text { High } \\
\text { protection }\end{array}$ & 1.03 & 1.01
\end{tabular}

\section{B. Measurements of Contact Angle}

Contact angle values measured on the surface of untreated cotton fabric were shown on figure 1. 


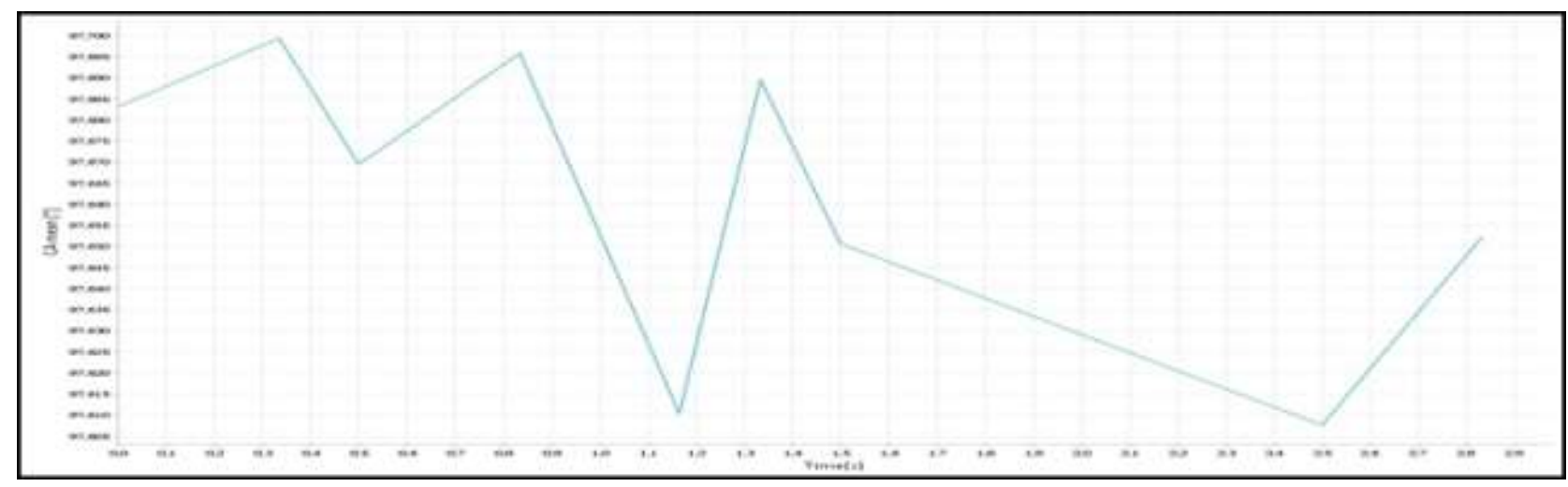

Fig 1. measurements contact angle of un- treated with nanomaterial cotton fabric

As shown on Figure 1, any values were not able to be taken because water drop was spread after $2.50 \mathrm{~s}$. Contact angle value was found as $97.5^{\circ}$ on average.
Contact angle values measured on the surface of $100 \%$ cotton denim fabric treated by nano-zinc oxide were shown on Figure 2.

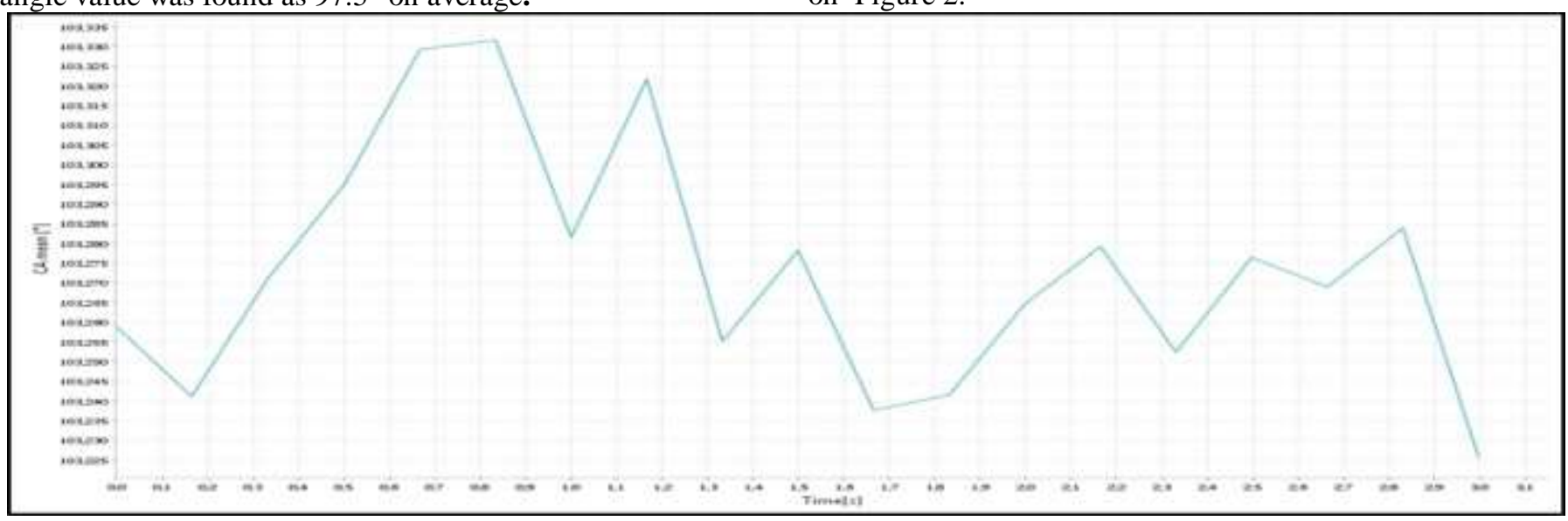

Fig. 2. Measurements contact angle of treated cotton fabric with $\mathrm{ZnO}$ nanomaterial

As seen on Figure 3, contact angle value was found as $103^{\circ}$ on average.

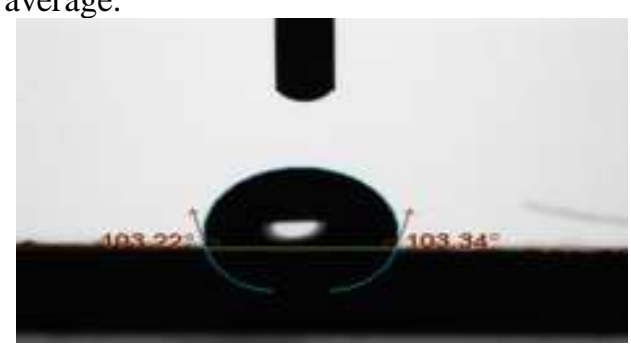

Fig. 3. The view of contact angle on the surface of cotton fabric treated by nano- $\mathrm{ZnO}$

\section{CONCLUSION}

This paper gives a brief overview of recent studies on nanometal thin flms which offer great promise for the development of various industrial products. Although practical application of these flms is still limited, the obstacles to application are being surmounted. The wettability of a textiles surface is a complex property and affects various other functional properties. Basic research on the control of the wettability of denim materials has just started. This is a key technology for textiles industries, and further investigations are expected in this feld.

When the surface contact angle values of the cotton fabric at finish treatment with zinc oxide nano particles were examined, it was seen that contact angle values of the coatings made by this nano-metal oxide increased by means of the water drop.

UV tests indicated a significant improvement in the UV absorbing activity of the nano- $\mathrm{ZnO}$ coated cotton fabric and it was found to have significant UV blocking properties.

\section{REFERENCES}

[1] J.L. Hoon, Bacteriostasis and Skin Innoxiousness of Nano size Silver Colloids on Textile Fabrics, Text. Res. J., 75 (7), 551, 2005, pp. 551556.

[2] G.E. İbrahim, J. Am. Sci, "Designing and Producing Fabrics Suitable for Being Used as Waterproof Raincoats," Journal of American Science, vol.7, no.10, pp.532-544, 2011.View at Google Scholar.

[3] I. Padleckiene, D. Petrulis, "Monitoring Flexing Fatigue Damage in the Coating of a Breathable-Coated Textile," Fibres Textiles in Eastern Europe, vol. 18, no. 2, pp. 73-77, 2010. View at Google Scholar.

[4] C. Wang, M. Li, G. Jiang and A. Tian, , "Cotton fabric coated with nano $\mathrm{TiO}_{2}$-acrylate copolymer for photocatalytic self-cleaning by in-situ suspension polymerization, "Applied Surface Science, vol .257, no. 20, pp. 8451-8456 , 2007. View at Google Scholar

[5] Z. Shi,I. Wyman, G. Liu, H. Hu and J. Hu, Handbook of Specialty Fluorinated Polymers, Banerjee, Oxford, UK, 2015.

Nilgün BECENEN was born in Edirne-TURKEY. She graduated from Yildız Teknik University in 1989 and received her Ph.D. at Namık Kemal University in 1989. She is assistant Professor at Vocational College of Technical Sciences of Trakya University. 